\title{
A Study on Need Satisfactions, Causality, Orientations and Subjective Well Being
}

\author{
Cicilia Chettiar \\ ${ }^{1}$ Asst. Professor and Head, Department of Psychology, Maniben Nanavati Women's College, \\ Mumbai. \\ E-mail-ciciliachettiar@yahoo.com
}

\begin{abstract}
The authors investigated the possible differences between two cultures on the different processes that lead to Subjective Well Being (SWB) as per self determination theory. A survey was conducted between 100 Tamilian and Keralite men and women using the scales for need satisfaction, causality orientation and SWB. Results show that although there were no significant differences in the actual levels of all three variables, the correlation between needs, causality orientations and SWB differed for both groups. Gender differences were also noticed. A regression equation was computed to understand how well the needs and the orientations were predictive of SWB. The differences in the two groups can be explained by the differences in culture.
\end{abstract}

Key words: need satisfaction, causality, orientations, subjective well being.

\section{INTRODUCTION}

Need satisfaction directs goal oriented behavior. Self - determination theory (SDT) [1] follows a route that connects the two schools of thought in need satisfaction research and offers an innovative way to study needs. Here, needs are innate like the drive reduction school of thought, yet they are at the psychological level as Murray theorized. Specifically, SDT identifies the needs for competence, relatedness and autonomy as essential for understanding the context and process of pursuing goals [1]. Competence is the need to perform a behavior without a biological requirement. Relatedness is the desire to connect to others. Autonomy concerns the experience of integration and freedom [2]. These three needs can be satisfied while engaging in a wide variety of behaviours, yet may be manifested differently in different cultures. Higher need satisfaction levels lead to a greater experience of SWB.

When relationships provide greater need satisfaction, the quality of relationships improve [3] leading to greater well being. Even daily fluctuations in need satisfaction affect daily well being [4]. SDT specifically suggests autonomy is an essential need for psychological growth and well-being regardless of cultural backdrops and values. An opposing view by the relativists is that psychological needs are not universal, rather a product of social norms [5]. If this is true then different cultures should affect psychological need satisfaction differently. This study hence decided to verify the relationship between satisfaction among autonomy need and well-being in two different cultures. 


\section{Causality Orientations}

SDT uses the concept of regulatory styles to explain individual differences referred to as Causality Orientations in SDT [6]. An individual with Autonomy Orientation $(A O)$ will respond to those factors that promote intrinsic motivation. They are drawn to situations that are challenging but not futile and provide useful feedback. Control Oriented (CO) individuals are driven by external rewards and pressures. This could either be through events or other people affecting actions. Impersonal orientation (IO) measures how much intentionality exists in the actions of an individual. These are individuals who believe outcomes are dependent on unknown factors.

These three orientations motivate individuals in every sphere of life. Their sense of self follows the narrow guidelines of their respective orientations [6-7]. There are personal differences that explain the actions of individuals. Researchers have shown similarity between $\mathrm{AO}$ and $\mathrm{CO}$, a finding that has been replicated in this study [8]. SDT claims that the extent to which needs are satisfied will determine what are the conditions leading to enhanced well being [9]. The interaction between basic needs and the social world will identify the individual differences in motivational orientation. It is believed that environments that disallow need satisfaction promote an IO and this along with $\mathrm{CO}$ style creates a negative effect on performance and well-being. We conclude therefore, that satisfaction of the three needs of autonomy, competence and relatedness, leads to an autonomous orientation and the outcome is finally greater well being. The theorists do not specify that only the satisfaction of autonomy need will lead to an autonomous orientation. Rather they believe that both in turn will lead to improved well being. This can be hypothesized to be a route beginning with autonomy need satisfaction, leading to increased $A O$ and finally ending in the perception of enhanced well being.

\section{The Impact of Culture}

We need to look at how society intervenes in the satisfaction of needs and thereby the development of a particular type of causality orientation. Early social science research acknowledged observable differences in social values and tendencies. The most influential distinction arose between individualistic and collectivist cultures [10-11]. Cross cultural studies follow the system of comparisons between countries which are drastically different like Belgium and Canada [12], U.S. and Belgium [13], U.S. and Russia. According to Hofstede [14], a national culture permeates the social environment in which children grow up. The same applies to regional cultures. In both cases children unconsciously and consciously pick up the values of the nation and more strongly the region. Although unrelated to SDT, it highlighted how differences within states of one country emerge given the right theoretical framework.

Extending this thought to SDT, we can hypothesize that the constructs explaining SWB in SDT could be different in people from the same country but different geographical regions. We attempt to highlight this difference within the two Indian states of Tamil Nadu and Kerala within the SDT framework. In selecting these two states, the researchers have taken into account the controversies associated with cross cultural comparative studies. Researchers have identified three concerns in conducting cross cultural studies [15]. They are: whom to compare, on what basis to compare and how to ensure measure equivalence. Their solution is to select groups on conceptual grounds rather than convenience, compare the groups on the basis of a theoretical model and ensure measure equivalence through appropriate procedures. Here, measure equivalence is ensured by studying two regional groups but currently in the same 
geographical area. Further these groups have lived together over a number of years and have been exposed to each other as well as other cultures in equal measure.

By studying both groups in the same neighbourhood, but in a third city, the researchers have ensured that both groups have been exposed to a third culture and the possible similarities could be due to the third culture but the differences would be due to their own cultural differences as identified in other studies [16]. Malgady and Johnson [15] confirm the "unique research opportunities" such a sampling technique provides. Finally, since the attempt is to systematically explore model driven hypotheses in relation to SDT, we selected measures specifically measuring SDT related constructs.

\section{Tamil Nadu and Kerala}

Tamil Nadu and Kerala are situated in the southern part of the Indian subcontinent. A large part of the cultural difference originated in the geography of the two regions. Kerala receives rainfall more often in the year than Tamil Nadu and its extensive network of waterways within the state ensures that it has no shortage of water. Tamil Nadu also receives rainfall in a similar pattern but does not have the distinctive internal waterway system. Also water distribution is not equal through the state and significant parts are arid.

One very obvious impact is the difference in living conditions between the two states. Tamil Nadu for years has shown clustered habitation around the available water source. This has lead to a collectivist life style. Interdependency stemming from this lifestyle is a part of the culture still observed among Tamilians even if they migrate to other places. Kerala on the other hand has historically exhibited an individual habitation style. Each family had their own food resources which could be individually grown thanks to the ample water supply. The different living conditions have deeply affected their independence or interdependence. It continues to exist even when they move to a different region.

According to SDT the three basic needs are universal and must be satisfied in all cultures. Tamilians and Keralites should not show any difference in their need satisfaction levels and causality orientation. Culturally, India has a pronounced tendency towards inequality between both sexes on most matters. The freedom men and women have is noticeably different in all spheres of life. We expect this difference to be reflected in the study. Though SWB is the final outcome and both groups and genders will find their own path to achieve it, those paths maybe different from each other. Finally, the study will show that the interaction between needs and the type of causality orientation will differ for both groups because of their cultural differences.

The hypotheses for this study are:

- There will be no difference in the need satisfaction levels and causality orientations of both cultures.

- There will be gender differences both within and between the two groups on need satisfaction and causality orientations.

- There will be no difference in the overall SWB of both groups and genders.

- The autonomy need will predict an SWB and an AO in both groups.

- AO will predict SWB in both groups. 


\section{METHODOLOGY}

We took a sample $(n=100)$ of individuals from the Goregaon area of Mumbai. It included 22 Tamil males, 27 Tamil females 30 Keralite males and 21 Keralite females. The mean age in the four groups was 32.5, 32.9, 28.7 and 35.8 years respectively. The participants were recruited by the snowball technique. Individuals worshipping at a specific church and temple in Goregaon were contacted and they continued referring other members belonging to the same community and living in the same area. This ensured that the sample included individuals who were equally exposed to the cultural practices of their region of origin as practiced in Goregaon.

\section{Procedure}

The questionnaires were given to the participants in a group setting and they had to fill them on the spot. It was ensured that all participants were above 18 and had a minimum work experience of at least 6 months. Further only those individuals who had lived in Goregaon continuously for a period of at least fifteen years were selected.

\section{Measures Used}

The Basic Needs Satisfaction Scale (BNSS) for general use has been successfully used to assess the extent to which the needs of autonomy, competence and relatedness have been satisfied in the subjects [17]. The General Causality Orientation Scale (GCOS) [7] measures the causality orientations in individuals. The scale consists of 17-vignettes. The third scale is the Subjective Well-being Inventory (SWBI) [18]. Reliability of the scales yielded Cronbach's alpha of 0.73 (BNSS), $0.84(\mathrm{SWBI})$ and 0.84 (GCOS).

\section{RESULTS}

Results show no statistically significant difference in the need satisfaction levels between the two groups. However relatedness need is highest in Tamilians whereas competence need is highest is Keralites. Both groups show positive correlation between the three needs, the needs and SWB and between CO and IO. Gender differences in the three needs point to greatest satisfaction of relatedness need in Tamil men and lowest in Keralite men. The difference in the levels of need satisfaction for relatedness was significant between Tamil men and women. Significant differences were noticed in the regression on needs, orientations and SWB in both groups (Table 1).

\section{DISCUSSION}

The first hypothesis expecting no difference in need satisfaction level between the two groups was confirmed. In the group we also find all participants show greater inclination for an autonomous orientation. This confirms the second part of the first hypothesis that there will be no difference between the groups in their causality orientation. SWB is positively correlated with $A O$ but negatively with both $\mathrm{CO}$ and IO. This indicates that individuals following an $A O$ have a healthier outcome than those oriented otherwise. And although $\mathrm{CO}$ is positively associated with AO there is no confirmation that it will lead to higher SWB (Table 2). 
Table 1: Showing Mean and SD for Keralite and Tamil, men and women on all the variables

\begin{tabular}{|c|c|c|c|c|c|c|c|c|c|}
\hline & & & SWB & Auto & Comp & Reltd & AutoOri & ContrOri & ImpOri \\
\hline \multirow[t]{6}{*}{ Kerala } & Female & Mean & 76.95 & 4.90 & 5.00 & 5.00 & 90.00 & 65.43 & 62.48 \\
\hline & & SD & 18.53 & 0.94 & 0.95 & 0.84 & 11.81 & 11.87 & 9.64 \\
\hline & Male & Mean & 79.43 & 4.93 & 5.03 & 4.97 & 88.30 & 66.63 & 58.93 \\
\hline & & SD & 15.48 & 0.87 & 0.96 & 0.81 & 15.57 & 12.53 & 11.81 \\
\hline & Total & Mean & 78.41 & 4.92 & 5.02 & 4.98 & 89.00 & 66.14 & 60.39 \\
\hline & & SD & 16.67 & 0.89 & 0.95 & 0.81 & 14.04 & 12.16 & 11.01 \\
\hline \multirow[t]{6}{*}{ Tamil } & Female & Mean & 76.59 & 4.93 & 5.19 & 5.11 & 88.00 & 68.19 & 59.74 \\
\hline & & SD & 16.79 & 0.78 & 0.88 & 0.85 & 12.82 & 10.09 & 12.88 \\
\hline & Male & Mean & 81.00 & 5.27 & 5.32 & 5.59 & 92.82 & 69.59 & 58.95 \\
\hline & & SD & 17.39 & 1.08 & 1.25 & 0.85 & 12.56 & 14.73 & 14.21 \\
\hline & Total & Mean & 78.57 & 5.08 & 5.24 & 5.33 & 90.16 & 68.82 & 59.39 \\
\hline & & SD & 17.03 & 0.93 & 1.05 & 0.88 & 12.81 & 12.27 & 13.35 \\
\hline \multirow[t]{6}{*}{ Total } & Female & Mean & 76.75 & 4.92 & 5.10 & 5.06 & 88.88 & 66.98 & 60.94 \\
\hline & & SD & 17.38 & 0.85 & 0.90 & 0.84 & 12.30 & 10.87 & 11.54 \\
\hline & Male & Mean & 80.10 & 5.08 & 5.15 & 5.23 & 90.21 & 67.88 & 58.94 \\
\hline & & SD & 16.17 & 0.97 & 1.09 & 0.88 & 14.42 & 13.45 & 12.75 \\
\hline & Total & Mean & 78.49 & 5.00 & 5.13 & 5.15 & 89.57 & 67.45 & 59.90 \\
\hline & & SD & 16.76 & 0.91 & 1.00 & 0.86 & 13.39 & 12.23 & 12.16 \\
\hline
\end{tabular}

\begin{tabular}{|c|c|c|c|c|c|c|c|c|}
\hline & & SWB & Auto & Comp & Reltd & AutoOri & ContrOri & ImpOri \\
\hline \multirow[t]{2}{*}{ SWB } & Kerala & \multirow[t]{2}{*}{1} & & & & & & \\
\hline & Tamil & & & & & & & \\
\hline \multirow[t]{2}{*}{ Auto } & Kerala & $.417 * *$ & \multirow[t]{2}{*}{1} & & & & & \\
\hline & Tamil & $.450 * *$ & & & & & & \\
\hline \multirow[t]{2}{*}{ Comp } & Kerala & $.456 * *$ & $.404^{* *}$ & \multirow[t]{2}{*}{1} & & & & \\
\hline & Tamil & $.461^{* *}$ & $.809 * *$ & & & & & \\
\hline \multirow[t]{2}{*}{ Reltd } & Kerala & $.438^{* *}$ & 0.274 & $.390 * *$ & \multirow[t]{2}{*}{1} & & & \\
\hline & Tamil & $.356 *$ & $.580 * *$ & $.568 * *$ & & & & \\
\hline \multirow[t]{2}{*}{ AutoOri } & Kerala & $.291^{*}$ & 0.182 & $.329 *$ & 0.072 & \multirow[t]{2}{*}{1} & & \\
\hline & Tamil & 0.123 & 0.252 & 0.223 & 0.151 & & & \\
\hline \multirow[t]{2}{*}{ ContrOri } & Kerala & -0.053 & -0.029 & 0.019 & -0.071 & 0.274 & \multirow[t]{2}{*}{1} & \\
\hline & Tamil & $-.329 *$ & -0.247 & $-.394 * *$ & -0.196 & 0.218 & & \\
\hline \multirow[t]{2}{*}{ ImpOri } & Kerala & -0.157 & -0.166 & -0.217 & -0.006 & -0.051 & $.616 * *$ & \multirow[t]{2}{*}{1} \\
\hline & Tamil & $-.441 * *$ & $-.378 * *$ & $-.465 * *$ & $-.302^{*}$ & -0.038 & $.664 * *$ & \\
\hline
\end{tabular}


There is a significant difference between genders with Tamil men finding a greater satisfaction of relatedness need as compared to the Tamil women that can be explained by the predominantly patriarchal system among them [19]. Among Keralites, greater need satisfaction for relatedness is shown among women although the difference is not statistically significant. The difference in the satisfaction of the relatedness need reinforces the theory that Tamilians with their clustered living have greater opportunity for connectedness and this aspect of their social life continues even after they migrate to a different culture. Causality orientations and SWB were not significantly different for the genders both within and between the groups confirming the third hypothesis. The association between needs and causality orientations show differences that can be explained through their cultural difference. The tendency to seek out challenging but stimulating opportunities reflects a possibility that other non intrinsic, socially relevant goals have been met. This explains the Keralite's relationship between competence need and AO. In Tamilians, the lack of an association between AO and the three needs or SWB show that the path to well being is not necessarily through AO. They may not find challenging situations and internalizing of environmental values conducive to well being.

Linear regressions were conducted for each group. For the Keralites, need for competence and relatedness predicted SWB whereas for Tamilians only competence need predicted SWB. This does not follow SDT theory that autonomy need is the strongest predictor of SWB. Competence need is the need to have a direct impact on the environment and to obtain valued outcomes from it. Producing an outcome even in the face of environmental pressures is empowering leading to an increase in SWB. This explains why satisfaction of the competence need predicts SWB among both Tamilians and Keralites. In table 3 given below Note: $\mathrm{R}^{2}=.208$ for step 1; Delta $\mathrm{R}^{2}=.08$ for step $2\left({ }^{*} \mathrm{p}<.005\right), R^{2}=.212$; Delta $R^{2}=.212\left(^{*} p<.005\right.$. Entries in italics refer to results for Tamils.

Causality orientation styles were also regressed to see which would most effectively predict SWB. AO is not predicted by any of the needs in Tamilians. A tentative reason is that being part of a collectivist culture, Tamilians naturally don't feel comfortable with autonomous functioning. In the case of Keralites, competence need predicts $A O$. We therefore reject the fourth hypothesis for both groups that autonomy need will predict an AO. In table 4, Note: $R^{2}=.085$; Delta $R^{2}=$ $.085\left({ }^{*} \mathrm{p}<.05\right), R^{2}=.194 ;$ Delta $R^{2}=.194\left(^{*} p<.005\right)$. Once again data in italics refers to the Tamil sample.

Relatedness need shows an association with SWB only in Keralites. As per SDT, individuals indulge in behaviors satisfying those needs which have been thwarted repeatedly. Finding opportunity to fulfill these needs therefore leads to an increase in SWB. The Tamilians form clustered settlements whereas Keralites form nucleated settlements [20]. Its follows quite logically that Tamilians have a greater opportunity to fulfill the relatedness needs, but the downside of this opportunity is that they are more subject to societal pressures and norms. This affects the quality of connectedness and could be the reason why satisfaction of the relatedness need does not lead to an increase in SWB in Tamils. Causality orientations in Keralites follows the path theorized by SDT, autonomous orientation leads to SWB. In Tamils this path is not replicated. What we see instead is a reversal, with IO 
Table 3: Results of multiple regressions for the two groups showing need satisfaction and SWB

\begin{tabular}{|c|c|c|c|}
\hline $\begin{array}{l}\text { Keralites } \\
\text { (Tamils) }\end{array}$ & B & SE B & Beta \\
\hline Step 1 & & & \\
\hline Constant & $38.17(39.41)$ & $11.409(11.21)$ & \\
\hline Competence need & 8.02 & 2.234 & $.456^{*}$ \\
\hline Competence & 7.47 & 2.10 & $.461^{*}$ \\
\hline Step 2 & & & \\
\hline Constant & 17.375 & 14.141 & \\
\hline Competence need & 5.92 & 2.33 & $.337^{*}$ \\
\hline Relatedness need & 6.29 & 2.72 & $.307^{*}$ \\
\hline
\end{tabular}

Table 4: Results of stepwise multiple regressions for the two groups showing causality orientations and SWB

\begin{tabular}{|c|c|c|}
\hline $\begin{array}{l}\text { Keralites } \\
\text { (Tamils) }\end{array}$ & B & Beta \\
\hline Constant & 47.64(111.957) & $14.619(10.157)$ \\
\hline $\begin{array}{l}\text { Autonomy } \\
\text { Orientation }\end{array}$ & .346 & .162 \\
\hline $\begin{array}{l}\text { Impersonal } \\
\text { Orientation }\end{array}$ & -.562 & .167 \\
\hline
\end{tabular}

showing a greater ability to predict lower SWB. Culturally explaining this, we can say that Tamilians have been traditionally dependent on the rain gods to fulfill their needs. Tamil Nadu being an arid state has to contend with non availability of a basic resource, namely water. This has made them largely karma oriented. They have traditionally placed their future in the hands of fate and this has made them less than happy with their living conditions. With irrigation and canal systems, Tamilians found that they did have a greater say in their future and they could affect the environment and their lives. Feeling competent enough affect their fortunes improves their SWB. Although this concept explains how Tamilians have lived over hundreds of years, we find an echo of the same thought process even in present day Tamilians.

Different people respond differently to same events. The results of this study indicate that although individuals belong to the same country, regional differences have to be taken into account while understanding their well being. Both Keralites and Tamilians show no indication of following SDT exactly as theorized. AO predicted SWB only in the Keralite group and not the Tamils. The reasons for this should be studied further to understand the implications for SDT. The prediction of SWB by competence and relatedness needs and negatively by IO in Tamilians, raises the question on how much one can generalize the results of SDT to all cultures.

Limitations to be remembered in this study are the sample size and the restriction of the sample to only one part of the city. This study should be 
expanded to include other parts of the city and to have a larger sample size.

\section{REFERENCES}

1. Deci $E L$, Ryan RM. The empirical exploration of intrinsic motivational processes. In $\mathrm{L}$ Berkowitz (Ed.), Advances in experimental social psychology (Vol. 13, pp. 39-80). New York: Academic; 1980.

2. Ryan RM. Agency and organization: Intrinsic motivation, autonomy and the self in psychological development. In J Jacobs (Ed.), Nebraska symposium on motivation: Developmental perspectives on motivation (Vol. 40, pp. 1-56). Lincoln: University of Nebraska Press ; 1993.

3. La Guardia JG, Ryan RM, Couchman CE, Deci EL. Within-person variation in security of attachment: A self-determination theory perspective on attachment, need fulfillment, and well-being. J Personal Soc Psychol 2000;79:367-84.

4. Reis HT, Franks P. The role of intimacy and social support in health outcomes: Two processes or one? Parental Relation 1994;2:185-97.

5. Lynch M. Basic needs and well-being: A self-determination theory view. Retrieved from http://counselingoutfitters.com/vistas/vistas10/Article 70.pdf ; 2010

6. Deci EL, Ryan RM. Intrinsic motivation and self-determination in human behavior. New York: Plenum ; 1985a.

7. Deci EL, Ryan RM. The general Causality Orientations Scale: Self Determination in Personality. J Res Personal 1985b;19109-34.

8. Koestner R, Zuckerman M. Causality orientations, failure, and achievement. J Personality 1994;62:321-46.

9. Deci EL, Ryan RM. The "what" and "why" of goal pursuits: Human needs and the selfdetermination of behavior. Psychol Inq 2000;11;227-68.

10. Hofstede G. Dimensions of national cultures in fifty countries and world-related values. In J Deregowski, S Dzuirawiec, R Annis (Eds.), Explications in cross-cultural psychology (pp. 335-355). Lisse, the Netherlands: Swets and Zeitlinger ; 1983.

11. Triandis HC. Individualism and collectivism. Boulder, CO: Westview ; 1995.

12. Ryan RM, Chirkov VI, Little TD, Sheldon KM, Timoshina E, Deci EL. The American Dream in Russia: Extrinsic aspirations and well-being in two cultures. Personal Soc Psychol Bull 1995;25:1509-24.

13. Deci EL, Ryan RM, Gagné M, Leone DR, Usunov J, Kornazheva BP. Need satisfaction, motivation, and well-being in the work organizations of a former Eastern Bloc country. Personal Soc Psychol Bull 2001;27(8):930-42.

14. Hofstede G. Culture's consequences: Comparing values, behaviors, institutions and organizations across nations. Thousand Oaks, CA: Sage ; 2001.

15. Johnson PB, Malgady R. Cultural/Ethnic Comparisons: A Research Agenda. J Gend Cult Health 1999;4(3):171-86.

16. Michael SM. Culture and Urbanization. Inter-India Publications: India ; 1989.

17. Broeck A, Vansteenkiste M, Witte $H$, Soenens B, Lens W. Capturing autonomy, competence, and relatedness at work: Construction and initial validation of the Work-related Basic Need Satisfaction scale. J Occupn Organiz Psychol 2010;83(4):9811002.

18. Nagpal R, Sel, H. SWB Inventory. World Health Organization. Regional Health Paper. SEARO. No. $24 ; 1992$.

19. Selvanayagam I. Tamil Nadu: Confrontation, Conplementarity, Compromise. Geneva: WCC Publications ; 1996.

20. Karve I. The Indian Village. Rural Sociology in India. New Delhi ; 1969.

Acknowledgements - Nil

Conflict of Interest - Nil

Funding - Nil. 